\title{
CRATER LAKE HABITAT PREDICTS MORPHOLOGICAL DIVERSITY IN ADAPTIVE RADIATIONS OF CICHLID FISHES
}

\author{
Hans Recknagel, ${ }^{1,2}$ Kathryn R. Elmer, ${ }^{1,2}$ and Axel Meyer ${ }^{1,3}$ \\ 'Lehrstuhl für Zoologie und Evolutionsbiologie, Department of Biology, University of Konstanz, 78457 Konstanz, \\ Germany \\ ${ }^{2}$ Institute of Biodiversity, Animal Health and Comparative Medicine, College of Medical, Veterinary and Life Sciences, \\ University of Glasgow, Glasgow G12 8QQ, United Kingdom \\ ${ }^{3}$ E-mail: axel.meyer@uni-konstanz.de
}

\begin{abstract}
Adaptive radiations provide an excellent opportunity for studying the correlates and causes for the origin of biodiversity. In these radiations, species diversity may be influenced by either the ecological and physical environment, intrinsic lineage effects, or both. Disentangling the relative contributions of these factors in generating biodiversity remains a major challenge in understanding why a lineage does or does not radiate. Here, we examined morphological variation in body shape for replicate flocks of Nicaraguan Midas cichlid fishes and tested its association with biological and physical characteristics of their crater lakes. We found that variability of body elongation, an adaptive trait in freshwater fishes, is mainly predicted by average lake depth $(N=6, P<0.001$, $\left.R^{2}=0.96\right)$. Other factors considered, including lake age, surface area, littoral zone area, number of co-occurring fish species, and genetic diversity of the Midas flock, did not significantly predict morphological variability. We also showed that lakes with a larger littoral zone have on average higher bodied Midas cichlids, indicating that Midas cichlid flocks are locally adapted to their crater lake habitats. In conclusion, we found that a lake's habitat predicts the magnitude and the diversity of body elongation in repeated cichlid adaptive radiations.
\end{abstract}

KEY WORDS: Adaptive morphology, adaptive radiation, benthic-limnetic, ecological opportunity, freshwater fish, habitat diversity.

\begin{abstract}
Adaptive radiations are crucial for understanding extant biodiversity because they have generated a great amount of morphological, ecological, and species diversity within relatively short timespans (Schluter 2000). Adaptive radiations usually occur in isolated geographic regions such as islands and lakes, which are colonized by one or few species that subsequently evolve into several, ecologically divergent forms. Some of the most prominent examples of adaptive radiations include Anolis lizards on Caribbean islands (Losos 2009), Darwin's finches on the Galapagos islands (Grant and Grant 2011), and cichlid fishes in crater lakes and great lakes (Meyer 1993; Turner 2007; Elmer et al. 2010a).

It is not fully understood why adaptive radiations occur in some lineages and environments while not in others. Eco-
\end{abstract}

logical opportunity, in the form of increased niche availability through low competition and habitat heterogeneity, is arguably the main factor determining whether diversification takes place and to which extent (Schluter 2000; Losos 2010). According to theory, diversifying selection is strongest in a population inhabiting a variable habitat where no or only few other species compete for the same resources; in that case intraspecific competition to exploit new resources ignites the diversification process. Comparative (e.g., Nosil and Reimchen 2005; Parent and Crespi 2009; Mahler et al. 2010; Wagner et al. 2012) and experimental (Rainey and Travisano 1998; Meyer and Kassen 2007) data have corroborated the significance of ecological opportunity in driving diversification. However, clearly not all lineages diversify 
even if ecological opportunity is available (Lovette et al. 2002; Arbogast et al. 2006). For example, mockingbird diversity on the Galapagos Islands does not compare to the diversity of Darwin's finches (Grant and Grant 2011). Similarly, contrasting diversification success has been reported in cichlid fishes, with some lineages remarkably prone to diversification whereas others completely fail to diversify even in the same environment (Koblmüller et al. 2006; Wagner et al. 2012; Elmer et al. 2013). Among the 250 or so species of the cichlid radiation within Lake Tanganyika, some tribes are very rich in species whereas other genera remain monotypic (Salzburger et al. 2005; Clabaut et al. 2007). Thus, not only environment but also lineage-specific factors also clearly play a role.

Studies on those lineages that do diversify have shown that adaptive traits, such as body morphology and feeding apparatus, are tightly linked to their biological and physical environment (Schluter 1993; Bernatchez et al. 1999; Losos 2009; Grant and Grant 2011) and increase in variability as a response to increased resource availability (Schluter 2000; Nosil and Reimchen 2005; Parent and Crespi 2009). Studies on young and ongoing adaptive radiations are ideal to understand the biotic and abiotic factors that generate biological diversity because, in contrast to older radiations, the initial conditions that promoted the diversification are more likely to still be the same (Coyne and Orr 2004). Among these, adaptive radiations of northern temperate lake freshwater fishes are by far the best-studied systems. The major axis of diversification occurs between fish inhabiting the benthic (shore and lake-bottom) and the limnetic (open-water) habitat. Numerous studies have associated a lack of interspecific competition (Robinson et al. 1993; Bourke et al. 1999; Vamosi 2003) and an increase in intraspecific competition (Bolnick 2004; Svanbäck and Bolnick 2007) with the degree of differentiation in adaptive traits related to either a benthic or a limnetic lifestyle. Another important factor driving differentiation is habitat heterogeneity, for example measured as lake depth (Hindar and Jonsson 1982; Vonlanthen et al. 2009) and lake surface area (Nosil and Reimchen 2005; Bolnick and Lau 2008). However, rivers, tributaries, and water level fluctuations often connect postglacial lakes, such that different lake populations are not always evolutionarily independent. Moreover, the presence of more than one ecotype within a species or a species complex inhabiting a lake (from here on referred to as a lake's species "flock") may be the result of multiple colonization events (e.g., McPhail 1993; Bernatchez et al. 1999; Jonsson and Jonsson 2001).

Here, we focus on the young incipient adaptive radiation of Neotropical Midas cichlid fishes in Nicaragua, which have colonized several crater lakes independently from two great lakes (Fig. 1) within the last 10,000 years (Barluenga and Meyer 2010; Elmer et al. 2013). The two big ancestral lakes (Great Lakes Nicaragua and Managua) are turbid and shallow (maximally 20 m depth), whereas the crater lakes have clear water, a conical bathymetry, and much greater depth (up to about $200 \mathrm{~m}$ ). Only two species of Midas cichlids live in the great lakes, while 11 endemic Midas species have been described in the crater lakes so far (Recknagel et al. 2013). Because this young adaptive radiation is at an early evolutionary stage, crucial factors driving the diversification can be better detected than they would be in an old adaptive radiation, in which the initial important factors in phenotypes under selection might have been superimposed by others with time (Coyne and Orr 2004). Crater lakes exemplify multiple independent "natural experiments": each lake is aquatically isolated and the Midas cichlid flock therein monophyletic (Barluenga and Meyer 2010). The Midas cichlids in these crater lakes are one of the few empirical examples of sympatric speciation in a vertebrate (Barluenga et al. 2006; K. R. Elmer et al., unpubl. ms.) and diversified rapidly (Wilson et al. 2000; Elmer et al. 2010b; Coyne 2011), suggesting a major role of natural selection during the speciation process. Each pristine crater lake environment allows us to have a close look at the characteristics of the Midas cichlid flock that has been shaped by natural selection.

Midas cichlid populations and species primarily differ in body shape, especially the extent of elongation (Meyer 1990; Elmer et al. 2010a). High versus elongated body shape is characteristically an indicator of adaptive diversification by disruptive selection within and along the benthic-limnetic axis in many freshwater fishes (such as in sticklebacks [e.g., McPhail 1994], whitefish [e.g., Østbye et al. 2006], and Arctic charr [e.g., Jonsson and Jonsson 2001]). Similarly, in Midas cichlids high-bodied fish are associated with the benthic habitat, whereas more elongated fish are more likely to occur in the limnetic habitat (Meyer 1990; Vivas and McKaye 2001; Barluenga et al. 2006; K. R. Elmer et al., unpubl. ms.). Fish with an "arrow-shaped" elongated body are putatively adapted to the open water as response to a selective pressure for higher acceleration speed (Webb 1984). In contrast, bulkier, higher bodied fish should be found closer to the shore, where maneuverability plays an important role (Dodds 2002). The extent of body elongation reflects this adaptive morphology. Ecological opportunity in the form of vacant and diverse habitats in the newly colonized crater lakes has possibly been the engine of this selection.

In the present study, we seek to identify the impact of physical and biological factors in characterizing the early stages in an incipient adaptive radiation. As a measurable trait of adaptive morphology for freshwater fishes (e.g., Schluter and McPhail 1992) we assessed the average, extent, and variability of body elongation of Midas cichlid flocks inhabiting six crater lakes. While some crater lakes might contain undescribed Midas cichlid species (Barluenga and Meyer 2010; Elmer et al. 2010a; Geiger et al. 2010a; Recknagel et al. 2013; Kusche et al. 2014), the 


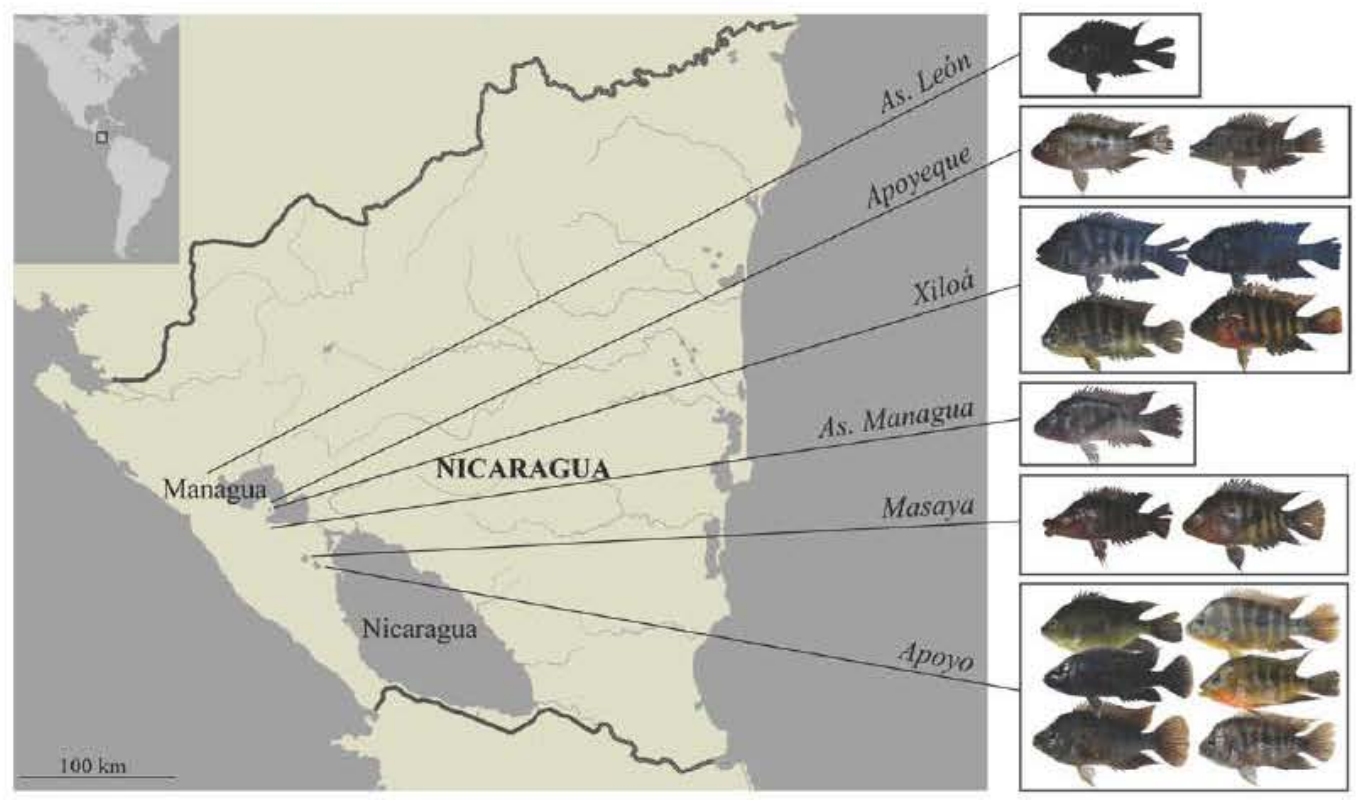

Figure 1. Map of Nicaragua including all surveyed water bodies. On the right side of the map the species flock of each crater lake is illustrated. As. $=$ Asososca.

variability in body elongation serves as an unbiased estimate to describe the scale of diversity and adaptive radiation.

We tested the hypothesis that the physical and biological characteristics of a crater lake predict the fish adaptive morphologies (summarized as body elongation) that have evolved therein We describe physical characteristics by the traits lake surface area, lake age, lake depth, and littoral zone size, and biological characteristics by the number of co-occurring fish species and the Midas cichlid flock's genetic diversity. We propose that ecological opportunity (here: lake depth, which is a proxy for habitat diversity, and number of co-occurring non-Midas cichlid fish species, as a measure of competition) might be associated with the amount of variability in adaptive morphology. We anticipated that genetic diversity might also explain an increase of variability in adaptive morphology. We further propose that the physical lake environment might determine the average adaptive morphology, as an indicator of local adaptation, and that the extent of adaptive morphology (i.e., maximally high-bodied or maximally elongated) might indicate restrictions or extremes of local crater lake niches.

\section{Methods}

Midas cichlid fishes (Amphilophus species complex) from the two great lakes of Nicaragua and six crater lakes were collected during a field expedition to Nicaragua from November to December 2010. Fifty adult individuals (at least $75 \mathrm{~mm}$ standard length) were randomly chosen from each of the eight investigated lakes (total $N=400$; Table 1). In lakes housing several species, the number of individuals per species was chosen based on the relative frequency of each species in that lake, estimated from large sampling collections (2001-2011) by the Meyer lab (Wilson et al. 2000; Bunje et al. 2007; Elmer et al. 2010a; K. R. Elmer et al., unpubl. ms.). For example, if a lake contained three different Midas species with the relative frequencies of $0.3,0.5$, and 0.2 , the number of individuals would have consisted of 15,25 , and 10 per species, respectively. This weighting allows us to identify proportional morphological characteristics of the flock in each lake. Additional analyses were conducted with each species separately to differentiate within and between species effects.

An elongation index was calculated for each fish as one minus the ratio of two linear measures, body depth (measured at anterior insertion of dorsal fin to insertion of pelvic fin) and standard length (EI $=1-$ [body depth/standard length]). Thus, fish with a higher elongation index are more elongated in body shape. The coefficient of variation of body elongation $\left(\mathrm{CV}_{\mathrm{EI}}\right)$ was obtained by dividing the standard deviation by the mean of EI within each lake and multiplying by $100\left(\mathrm{CV}_{\mathrm{EI}}=100 \times\left[\mathrm{EI}_{\mathrm{SD}} / \mathrm{EI}_{\mathrm{MEAN}}\right]\right.$ ) (Lewontin 1966). EI is a univariate parameter that we have developed to describe the major axis of variability (similar to PC1 in Elmer et al. 2010a) in Midas cichlids in particular and freshwater fishes in general. We use this measure because it is simple and adequately reflects the morphological variability identified previously (e.g., Elmer et al. 2010a). Microsatellite genetic diversity estimates for the Midas cichlid flock from each lake were drawn from Barluenga and Meyer (2010).

Physical and biological lake characteristics were collected from the literature (Waid et al. 1999; Elmer et al. 2010a). These 
Table 1. Characteristics of body elongation for Midas cichlid flocks (rows 1-4) and biological and physical characteristics (rows 5-11) listed for each of six crater lakes.

\begin{tabular}{|c|c|c|c|c|c|c|}
\hline Lake & Apoyeque & Apoyo & As. León & As. Managua & Masaya & Xiloá \\
\hline $\mathrm{EI}_{\text {MEAN }}$ & 0.56 & 0.57 & 0.55 & 0.59 & 0.55 & 0.56 \\
\hline $\mathrm{EI}_{\mathrm{MIN}}$ & 0.52 & 0.51 & 0.52 & 0.54 & 0.51 & 0.51 \\
\hline $\mathrm{EI}_{\mathrm{MAX}}$ & 0.62 & 0.66 & 0.58 & 0.63 & 0.59 & 0.60 \\
\hline $\mathrm{CV}_{\mathrm{EI}}$ & 4.96 & 7.99 & 3.62 & 4.50 & 4.11 & 5.48 \\
\hline Genetic diversity $^{1}$ & 0.58 & 0.59 & 0.42 & 0.52 & 0.74 & 0.67 \\
\hline Midas species $(\mathrm{N})^{1}$ & 2 & $6^{5}$ & 1 & 1 & 2 & $4^{4}$ \\
\hline Other species $(\mathrm{N})^{2}$ & 2 & 5 & 3 & 3 & 9 & 14 \\
\hline Mean depth $(\mathrm{m})^{2}$ & 52 & 142 & 17.2 & 54.3 & 41.7 & 60 \\
\hline Littoral zone $\left(\mathrm{km}^{2}\right)^{3}$ & 0.9 & 0.3 & 0.7 & 0.2 & 2.2 & 1.4 \\
\hline Surface area $\left(\mathrm{km}^{2}\right)^{2}$ & 2.5 & 21.1 & 0.8 & 0.7 & 8.4 & 3.8 \\
\hline Age (years) $)^{2}$ & 1900 & 23,890 & 4500 & 1245 & 6000 & 6100 \\
\hline
\end{tabular}

${ }^{1}$ Barluenga and Meyer 2010.

${ }^{2}$ Elmer et al. 2010a.

${ }^{3}$ Wald et al. 1999.

${ }^{4}$ Includes additions with Recknagel et al. 2013.

5 Includes additions with Gelger et al. 2010b.

included lake surface area, lake age, number of Midas cichlid species, number of competing fish species, size of the littoral zone, and average lake depth. Benthic species are ecologically associated with the littoral zone (Vivas and McKaye 2001). Estimates for the size of the littoral zone were taken from Waid et al. (1999), where it is defined as the bottom area of a lake from shore down to $15 \mathrm{~m}$ below surface. For the two great lakes, we calculated littoral zone size based on their bathymetric profiles (Cole 1976; Freundt et al. 2007). The number of competing species and average lake depth were chosen as factors affecting ecological opportunity. Competing species were defined as those fish species syntopically occurring with Midas cichlids and of a comparable size (larger than $10 \mathrm{~cm}$ standard length). Lake depth is treated as proxy for habitat diversity, since increasing water depths increase the physical and ecological diversity in the lake (see Ricklefs and Lovette 1999).

Statistical analyses were conducted in R (R Core Team 2012). Statistical analyses were carried out on six crater lakes, each characterized by different measures of Midas cichlid flock phenotypic characteristics, and physical and biological characteristics. The great lakes were excluded from all statistical analyses because the Midas cichlid species from these lakes are the ancestors of all crater lake Midas cichlid flocks and are therefore not relevant for testing adaptive divergence after colonization. Also, the history, geology, and chemistry of these lakes are fundamentally different from the crater lakes (see Elmer et al. 2010a). The parameters lake age, surface area, and littoral zone size were log transformed. Individual linear regressions were performed on each of the lake parameters and $\mathrm{EI}$ mean $\left(\mathrm{EI}_{\mathrm{MEAN}}\right)$, minimum $\left(\mathrm{EI}_{\mathrm{MIN}}\right)$, maximum ( $\left.\mathrm{EI}_{\mathrm{MAX}}\right)$, and coefficient of variation $\left(\mathrm{CV}_{\mathrm{EI}}\right)$ separately. $\mathrm{EI}_{\mathrm{MEAN}}$ indicates the average elongation of a lake's Midas cichlid flock. Since our EI estimate depends on the relative species frequencies, species that are less common have a lower effect than more abundant species on this estimate. This weighted correction for relative abundance allows us to test for the general appearance of a Midas cichlid flock in a specific crater lake. In addition, we assessed measures of $\mathrm{EI}_{\mathrm{MIN}}$ and $\mathrm{EI}_{\mathrm{MAX}}$ to test whether extreme phenotypes depend on certain lake parameters.

Correlations between predictive variables were assessed using Pearson correlation coefficient (PCC) and tested for significance. Because correlations can be more complex than between just two variables, we also pursued a multivariate approach by performing a principal component analysis (PCA) including all lake specific parameters. Additional pairwise linear regressions were performed on all principal components (PCs) and measures of body elongation ( $\mathrm{EI}_{\mathrm{MEAN}}, \mathrm{EI}_{\mathrm{MIN}}, \mathrm{EI}_{\mathrm{MAX}}$, and $\mathrm{CV}_{\mathrm{EI}}$ ) to check whether certain combined characteristics of a crater lake influenced body elongation.

\section{Results}

\section{CORRELATIONS AMONG CRATER LAKE CHARACTERISTICS}

None of the six predictive physical or biological variables (lake surface area, lake age, littoral zone size, mean lake depth, number of competing species, or Midas flock genetic diversity) exhibited significant collinearity among each other $(P>0.05$; Table S1). However, Pearson correlation coefficients were moderately high between some parameters ( 5 of 15 comparisons with PCC $\geq$ 0.65 ). A multivariate PCA mainly discriminated between crater 


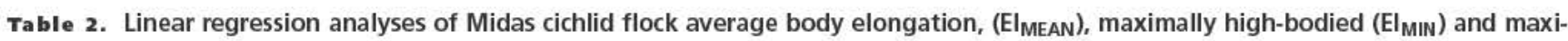
mally elongated (EI $\left.\mathrm{I}_{\mathrm{MAX}}\right)$ phenotypes, and variability in body elongation $\left(\mathrm{CV}_{\mathrm{El}}\right)$ regressed on lake characteristics.

\begin{tabular}{|c|c|c|c|c|}
\hline Variable & Coefficient & $t$-value & $P$-value & $R^{2}$ \\
\hline \multicolumn{5}{|c|}{ Body elongation ( $\mathrm{EI}_{\mathrm{MEAN}}$ ) } \\
\hline Genetic diversity & -0.028 & -0.417 & 0.698 & 0.042 \\
\hline Other species $(\mathrm{N})$ & -0.001 & -0.597 & 0.583 & 0.082 \\
\hline Mean depth (m) & 0.000 & 0.833 & 0.452 & 0.148 \\
\hline Littoral $\left(\mathrm{km}^{2}\right)$ & -0.033 & -3.004 & $0.040^{*}$ & 0.693 \\
\hline Surface $\left(\mathrm{km}^{2}\right)$ & -0.006 & -0.43 & 0.690 & 0.016 \\
\hline Age (years) & -0.011 & -0.727 & 0.507 & 0.117 \\
\hline \multicolumn{5}{|c|}{ Extreme high-bodied $\left(\mathrm{EI}_{\mathrm{MIN}}\right)$} \\
\hline Genetic diversity & -0.059 & -1.351 & 0.248 & 0.313 \\
\hline Other species $(\mathrm{N})$ & -0.001 & -1.458 & 0.219 & 0.347 \\
\hline Mean depth (m) & 0.000 & -0.633 & 0.561 & 0.091 \\
\hline Littoral $\left(\mathrm{km}^{2}\right)$ & -0.021 & -1.778 & 0.150 & 0.441 \\
\hline Surface $\left(\mathrm{km}^{2}\right)$ & 0.016 & -2.458 & 0.070 & 0.602 \\
\hline Age (years) & -0.021 & -2.653 & 0.057 & 0.638 \\
\hline \multicolumn{5}{|c|}{ Extreme elongated ( $\left.\mathrm{EI}_{\mathrm{MAX}}\right)$} \\
\hline Genetic diversity & 0.000 & 0.000 & 1.000 & 0.033 \\
\hline Other species $(N)$ & -0.002 & -0.611 & 0.574 & 0.085 \\
\hline Mean depth (m) & 0.001 & 3.812 & $0.019^{* *}$ & 0.784 \\
\hline Littoral $\left(\mathrm{km}^{2}\right)$ & -0.051 & -1.755 & 0.154 & 0.435 \\
\hline Surface $\left(\mathrm{km}^{2}\right)$ & 0.022 & 0.957 & 0.393 & 0.186 \\
\hline Age (years) & 0.016 & 0.505 & 0.640 & 0.060 \\
\hline \multicolumn{5}{|c|}{$\begin{array}{l}\text { Variability in body elongation } \\
\left(\mathrm{CV}_{\mathrm{EI}}\right)\end{array}$} \\
\hline Genetic diversity & 2.875 & 0.417 & 0.698 & 0.042 \\
\hline Other species $(N)$ & 0.036 & 0.219 & 0.837 & 0.012 \\
\hline Mean depth (m) & 0.036 & 10.370 & $0.0005^{* * *}$ & 0.964 \\
\hline Littoral $\left(\mathrm{km}^{2}\right)$ & -1.375 & -0.710 & 0.517 & 0.112 \\
\hline Surface $\left(\mathrm{km}^{2}\right)$ & 2.017 & 2.180 & 0.095 & 0.543 \\
\hline Age (years) & 2.314 & 1.834 & 0.141 & 0.457 \\
\hline
\end{tabular}

Significant $P$-values are marked with * for $P<0.05$, ** for $P<0.01$, and *** for $P<0.001$.

lakes that were older, larger, deeper, contained more species, a Midas flock with more genetic diversity, that had a larger littoral zone and those that showed the opposite pattern (Table S2, Fig. S1). In addition, the number of competing species and genetic diversity showed comparable directions in multivariate space, as did lake surface, lake age and lake depth, indicating that those characteristics are to some extent related within these crater lakes (Table S2, Fig. S1). However, except for lake depth none of these correlated predictive variables were significantly associated with any of the flocks' phenotypic characteristics $\left(\mathrm{EI}_{\mathrm{MEAN}}, \mathrm{EI}_{\mathrm{MIN}}\right.$, $\mathrm{EI}_{\mathrm{MAX}}$, and $\mathrm{CV}_{\mathrm{EI}}$ ) in pairwise linear regressions (see Table 2 and results below).

\section{MORPHOLOGICAL VARIABILITY INCREASES WITH SPECIES RICHNESS}

To assess whether our index of variability in adaptive morphology $\left(\mathrm{CV}_{\mathrm{EI}}\right)$ is an accurate reflection of currently described species in the Midas complex, we tested whether $\mathrm{CV}_{\mathrm{EI}}$ predicted Midas cichlid species richness. We found $\mathrm{CV}_{\mathrm{EI}}$ to be positively associated with Midas cichlid species richness (coefficient $=0.743, P=0.005, R^{2}=0.86$ ). This indicates that $\mathrm{CV}_{\mathrm{EI}}$ not only explains morphological variation in a Midas cichlid flock, but also the number of species of which the flock is composed.

\section{BODY ELONGATION ACROSS CRATER LAKES}

Mean body elongation varied across crater lakes (Table 1, Fig. 2A). Asososca Managua contained the most elongated $\left(\mathrm{EI}_{\mathrm{MEAN}}=0.59\right)$ while Asososca León and Masaya contained the most high-bodied flocks of Midas cichlids $\left(\mathrm{EI}_{\mathrm{MEAN}}=0.55\right)$.

With regard to extremes, there was little difference among crater lake populations in the extent of maximally high-bodied individuals (i.e., have the least body elongation; $\mathrm{EI}_{\mathrm{MIN}}=0.51-$ 0.52), except for Asososca Managua where the flock is the least 


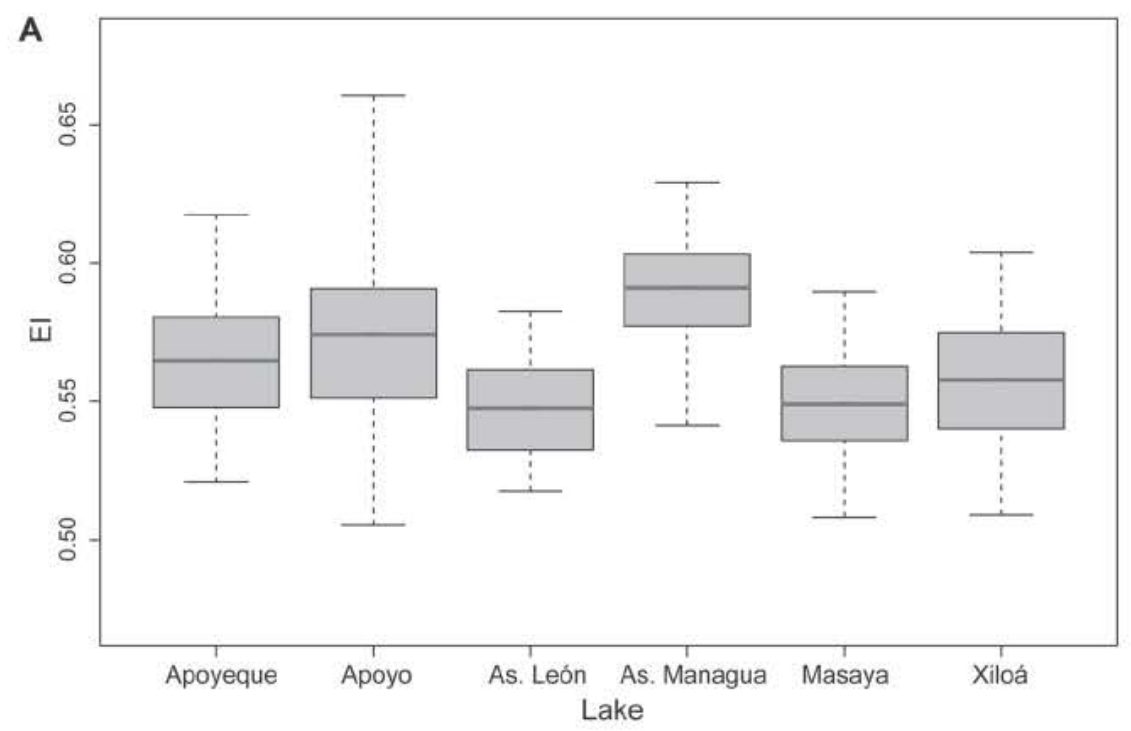

B

C
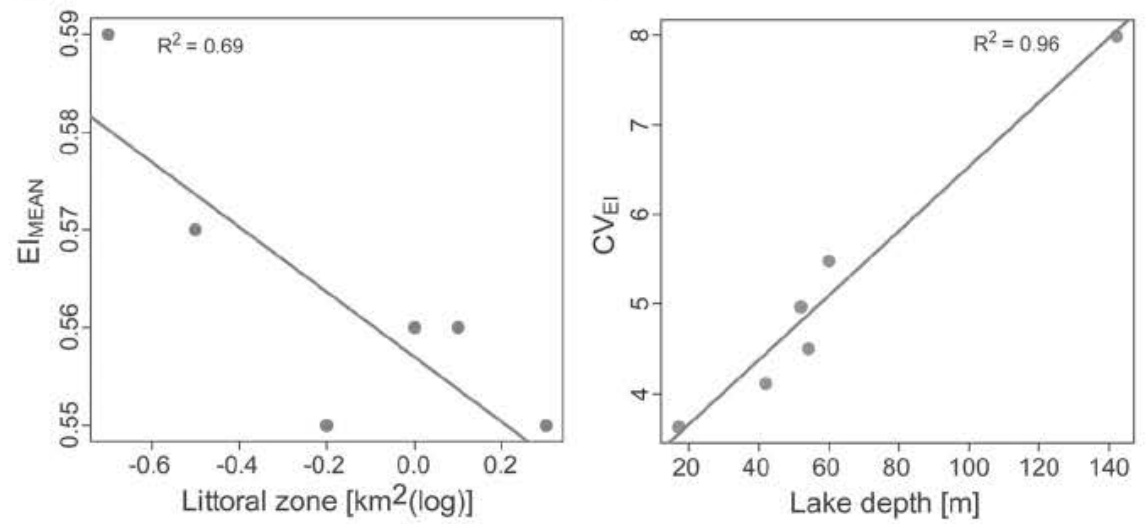

Figure 2. Body elongation across crater lakes. (A) Body elongation (elongation index, El) of Midas cichlid flocks across the six Nicaraguan

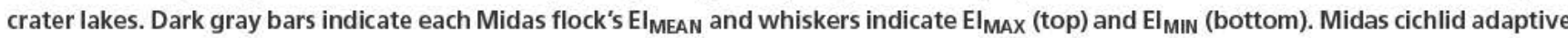
morphologies regressed against the main predictive environmental variable (see text and Table 2 ), (B) average (EI ${ }_{\text {MEAN }}$ ) body elongation and littoral zone area, and $(C)$ variability $\left(\mathrm{CV}_{\mathrm{EI}}\right)$ of body elongation and average lake depth. The coefficient of determination $\left(R^{2}\right)$ is indicated at the top of each panel (B and $C)$.

high-bodied $\left(\mathrm{EI}_{\mathrm{MIN}}=0.54\right)$ of any across the complex. In contrast, crater lake populations varied considerably in the maximum extent of elongation $\left(\mathrm{EI}_{\mathrm{MAX}}=0.58-0.66\right.$ ) (Table 1, Fig. 2A).

Variability in body elongation, $\mathrm{CV}_{\mathrm{EI}}$, ranged from 3.62 (crater lake Asososca León) to 7.99 (crater lake Apoyo) in Midas flocks across lakes (Table 1).

Great lake populations were not analyzed statistically but are noted here for comparison. Great lake Midas cichlids were more high-bodied than any crater lake flock, both on average (Managua $\mathrm{EI}_{\mathrm{MEAN}}=0.51$, Nicaragua $\mathrm{EI}_{\mathrm{MEAN}}=0.53$ ) and also in extent (Managua: $\mathrm{EI}_{\mathrm{MIN}}=0.46, \mathrm{EI}_{\mathrm{MAX}}=0.56$; Nicaragua $\left.\mathrm{EI}_{\mathrm{MIN}}=0.50, \mathrm{EI}_{\mathrm{MAX}}=0.58\right)$. Variability in body elongation in the great lakes was relatively low: Managua $\mathrm{CV}_{\mathrm{EI}}=4.71$, Nicaragua $\mathrm{CV}_{\mathrm{EI}}=3.99$.

\section{ASSOCIATION BETWEEN ENVIRONMENT AND BODY ELONGATION}

Average body elongation ( $\mathrm{EI}_{\mathrm{MEAN}}$ ) in a Midas flock significantly decreased with increasing littoral area (coefficient $=-0.033$, $P=0.040, R^{2}=0.69$, Fig. 2B). No other physical or biological variable (lake surface area, lake age, number of competing fish species, average lake depth) was significantly associated with $\mathrm{EI}_{\text {MEAN }}$ (Table 2). None of the principal components showed a significant relationship with $\mathrm{EI}_{\mathrm{MEAN}}$ (Table S3), indicating that the cumulative effect of the predictive variables on PC1-6 cannot predict $\mathrm{EI}_{\text {MEAN }}$. Therefore, the size of the littoral zone plays a significant role in predicting the average Midas cichlid body form; crater lakes with a larger littoral zone contained a more highbodied Midas cichlid flock. 
Minimum body elongation ( $\mathrm{EI}_{\mathrm{MIN}}$ ) was not associated with any biological or physical lake characteristics as assessed by pairwise linear regressions (Table 2). However, $\mathrm{EI}_{\mathrm{MIN}}$ significantly decreased with PC1 (Table S3). The parameter with the highest loading for this component was lake surface $(0.524)$, but all other lake variables also showed considerably high loadings $(0.262$ 0.458 ) (Table S2). This relationship is probably mainly driven by crater lake Asososca Managua (with the lowest value on PC1), considering that $\mathrm{EI}_{\mathrm{MIN}}$ did not vary much across crater lakes and that the most high-bodied individual in Asososca Managua was still substantially elongated compared to other lakes (see $\mathrm{EI}_{\mathrm{MIN}}$, Table 1).

The extent of elongation ( $\left.\mathrm{EI}_{\mathrm{MAX}}\right)$ in a flock significantly increased with lake depth (coefficient $=0.001, P=0.019, R^{2}=$ 0.78 ) (Table 2). A role for lake depth in predicting $\mathrm{EI}_{\mathrm{MAX}}$ was further suggested by a negative relationship with PC2 (coefficient = $-0.006, P=0.030, R^{2}=0.70$ ), with which lake depth had the most negative loading (Table S2). Hence, deeper lakes tend to contain a more maximally elongated Midas cichlid body shape.

We found a significant positive relationship between lake depth and $\mathrm{CV}_{\mathrm{EI}}$ (coefficient $=0.036, P=0.0005, R^{2}=0.96$ ). Deeper lakes tended to house a Midas cichlid flock that was more variable in body elongation (Fig. 2C). No other variable was significantly associated with $\mathrm{CV}_{\mathrm{EI}}$ (Table 2). Linear regressions of $\mathrm{CV}_{\mathrm{EI}}$ on PCs 1-6 were all nonsignificant (Table S3). When the analysis was conducted by species $(N=15)$, rather than by crater lake flock $(N=6), \mathrm{CV}_{\mathrm{EI}}$ did not increase with lake depth $\left(P=0.269, R^{2}=0.09\right)$, which indicates that intraspecific variability was not driving the positive relationship.

\section{Discussion}

\section{HABITAT PREDICTS LOCAL ADAPTIVE MORPHOLOGY}

We found that physical environment predicted body shape in a sympatric Midas cichlid flock; crater lakes with larger littoral zones housed on average higher bodied Midas cichlids (Fig. 2B). Because the littoral zone is structurally heterogeneous, for example with rocks and crevasses, maneuverability becomes important. It has been found more generally that benthic fishes tend to be more high-bodied and possess larger pectoral fins (Webb 1984). A higher body also allows for stronger musculature attachments related to the feeding apparatus, for example to optimize suction efficiency (Norton and Brainerd 1993; Holzman et al. 2012). In contrast, in the homogeneous open water habitat acceleration speed is key; fish adapted to the open-water tend to be more elongated with a fusiform body form and smaller pectoral fins, which functional morphology studies show facilitates swimming speed (Webb 1984). The greater microhabitat structure in the littoral zone is further illustrated by the presence of more Midas cichlid species inhabiting the littoral zone relative to the open-water (e.g., three benthic species and one limnetic species in Xiloá [Stauffer and McKaye 2002; Recknagel et al. 2013], five benthic species and one limnetic species in Apoyo [Barlow and Munsey 1976; Stauffer et al. 2008; Geiger et al. 2010b], K. R. Elmer et al., unpubl. ms.). Resource partitioning and niche specializations within the littoral zone might support larger population sizes of highbodied fishes, and ultimately facilitate speciation.

Relationships between ecological features and morphology have been identified in several adaptive radiations, such as in Caribbean Anolis lizards (Losos 2009), Darwin's finches (Grant and Grant 2011), and freshwater fishes (Schluter 2000). Research on benthic-limnetic species pairs of sticklebacks in postglacial lakes has shown that habitat use and morphology are tightly linked, with sticklebacks inhabiting littoral zones being more high-bodied than those in the limnetic zone (Schluter 1993; McPhail 1994). Lakes dominated by a limnetic environment also tend to house flocks with more limnetic-like sticklebacks (e.g., increased gill raker number and length) compared to lakes dominated by benthic environment (Lavin and McPhail 1985). Similarly, in whitefish (Østbye et al. 2006) and Arctic charr (Jonsson and Jonsson 2001), benthic-limnetic habitat use is associated with divergent morphologies. Despite their relatively old divergence times (Midas-stickleback: $\sim 105$ Mya; Midas-salmonids: $\sim 220$ Mya; stickleback-salmonids: $\sim 220$ Mya, following Matschiner et al. 2011; Near et al. 2012), similar morphological adaptations have evolved in these evolutionary disparate lineages, presumably in response to similar selective pressures (see also Elmer and Meyer 2011). In combination with our results, these studies emphasize that characteristics of a habitat can predict the direction of adaptive morphological traits across freshwater fish adaptive radiations.

\section{LAKE DEPTH PREDICTS MORPHOLOGICAL VARIABILITY AND EXTENT}

We found that deeper lakes, which presumably provide greater ecological opportunity through available and diverse habitats, tended to house a Midas cichlid flock with overall greater variability in body shape $\left(\mathrm{CV}_{\mathrm{EI}}\right)$. Deeper lakes also housed the most extremely elongate fishes ( $\mathrm{EI}_{\mathrm{MAX}}$ ) (Table 2) reflecting a limnetic ecomorphology. These deeper lakes presumably offer a greater potential for habitat isolation and diversification along the benthic-limnetic axis and therefore enhance the probability of establishing habitat-associated fitness peaks, ultimately leading to the formation of reproductively isolated Midas cichlid species (Barlow and Munsey 1976 and as modeled for sympatric speciation in Apoyo by Gavrilets et al. 2007).

The role of lake depth in promoting diversification might be a more general characteristic for fish radiations. For example, populations of Arctic charr frequently exhibit body shape polymorphisms and it has been shown that deep northern temperate lakes 
contain more ecomorphs than shallow lakes (Hindar and Jonsson 1982; Alekseyev et al. 2002). Pairs of stable benthic-limnetic stickleback species only occur in a few lakes in North America, and colonization history certainly plays an important role that ecotypes a lake contains, but the lake's morphometry is also crucial; only if the lake provides both a benthic and a limnetic habitat can the associated species pairs form (McPhail 1993). Lake depth was also the best predictor variable in the diversification of cichlid adaptive radiations in African Great Lakes (Wagner et al. 2012). In contrast, Landry et al. (2007) found that the most genetically and morphologically divergent pairs of whitefish ecomorphs occurred in shallow lakes, presumably as a result of increased intraspecific competition. In summary, our study supports lake depth as a major predictor for diversification in freshwater fishes; however, diversification in other lineages might also depend on factors such as intra- and interspecific competition, predator regime, and lineage effects.

While here we show that deep lakes favor the evolution of morphological diversity, this does not necessarily imply that more species evolved therein. Several studies have shown that intermediate selection gradients (e.g., a gently sloping lake bottom) facilitate speciation events whereas steep and shallow gradients impede speciation (Nosil and Crespi 2004; Gavrilets et al. 2007; Räsänen and Hendry 2008; Seehausen et al. 2008; Bolnick and Lau 2008). For example, lake Asososca Managua contains a morphologically variable Midas flock, but it has not diverged into benthic and limnetic species (see Table 1; Recknagel et al. 2013; Kusche et al. 2014). In that specific case, it is conceivable that the steep lake bottom of Asososca Managua in fact impedes speciation; however, this remains to be tested in future investigations.

The other component of ecological opportunity we assessed-number of competing (non-Midas) fish species-was not associated with variability in body elongation. A paucity of competing taxa is considered a key factor of ecological opportunity in general (Schluter 2000; Losos 2010) and plays a role for freshwater fish radiations in postglacial lakes in particular (Jonsson and Jonsson 2001; Vamosi 2003). For example, stickleback populations with sympatric benthic and limnetic ecomorphs were only found in lakes that contained no other fishes than cutthroat trout (Oncorhynchus clarki), presumably because these other species either compete for the same resources with sticklebacks or predate on them (Vamosi 2003). In general, Nicaraguan crater lakes are species-poor and the effect of competing fish species is thought to be negligible (Elmer et al. 2010a). Moreover, the Midas cichlid is the most abundant and most ecologically diverse cichlid fish found in Nicaraguan crater lakes (Barlow 1976; Elmer et al. 2010a). Cichlid lineages other than Midas cichlids have not radiated into flocks in any other Nicaraguan crater lake (Waid et al. 1999; Elmer et al. 2013). Presumably other cichlid fishes occupy different ecological niches or, alternatively, occupy the same niche but, given their much lower abundance, are inferior competitors compared to the Midas cichlid. It may be that Midas cichlids have an inherent propensity to adaptive radiation (Elmer et al. 2013).

In theory, crater lake flocks with higher genetic diversity (caused by various demographic and historical effects) might diversify more quickly in response to selection (Barrett and Schluter 2008). However, we found no evidence for a relationship between genetic and morphological diversity (Table 2). Similarly, in Arctic charr no relationship was found between neutral genetic variation and morphological differentiation (Hindar et al. 1986). In whitefish, lakes with the most morphologically divergent populations showed the highest genetic differentiation between ecomorphs (Renaut et al. 2011). However, higher genetic divergence does not necessarily imply that lakes with higher morphological diversity exhibit higher overall genetic diversity, the extent of which was not noted in that study. In general, it seems that there is no strong relationship between neutral genetic diversity and morphological diversity (Reed and Frankham 2001). In fact, it may be a common pattern of young adaptive radiations in isolated habitats that only few loci of presumably major effect play a strong role in divergence relative to a porous, and not necessarily particularly variable, genome.

\section{COLLINEARITY AMONG CRATER LAKE TRAITS}

We found that some of the crater lake traits were correlated to a certain extent, though none of them significantly. Collinearity among predictive variables can confound analyses, yet have been notoriously difficult to disentangle. Especially when several predictive variables are associated with one responding variable, it is difficult to decide which of those variables most likely predicts the outcome. For example, size and age of a region are factors known to positively correlate with species diversity in adaptive radiations (Gavrilets and Losos 2009). It has been suggested that the correlation between geographic area and species diversity can be explained by an increase of ecological opportunity in larger areas (MacArthur and Wilson 1967; Losos and Schluter 2000). Therefore, while species richness correlates with geographic area, ecological opportunity might be the ultimate cause driving species diversification. Diversity in adaptive radiations of African cichlids was, as here with Nicaraguan crater lake cichlids, dependent on lake depth (Wagner et al. 2012). This suggests that lake depth may play a major role in the adaptive radiation of cichlid fishes in general. Lake depth and lake age were correlated in Wagner et al. (2012), which imposed an effect of lake age on species diversity. While in our study the relatively high correlation coefficients suggest lake depth might be confounded with lake age and surface area, we only find a strong association between lake depth, but not lake age nor lake size, on body elongation variability. This agrees with other research that found morphological 
diversification in Midas cichlids can occur within only a few hundred generations (Elmer et al. 2010b), suggesting that Midas cichlid adaptive radiation is not restricted by time.

\section{Conclusion}

We found that environment predicts adaptive morphology in Midas cichlid fishes. Deeper lakes contained Midas cichlid flocks with a greater variability in body elongation and also housed the most maximally elongated cichlids. Size of the littoral zone predicted the average morphology in a flock, such that crater lakes with larger littoral zones overall contained a higher bodied Midas cichlid flock. More generally, we show the promise of using young adaptive radiations to study the impact of the natural environment on shaping diversity and suggest that freshwater fish adaptive radiations to some extent are predictable in their outcome.

\section{ACKNOWLEDGMENTS}

We thank H. Kusche, G. Machado-Schiaffino, M.-L. Spreitzer, R. Reyes and M. Pierotti for assistance in the field. We also thank J. Connor, T. Streelman, two anonymous reviewers, J. Losos, and B. Helm for providing helpful comments on the manuscript. We thank Ministerio del Ambiente y los Recursos Naturales (MARENA) for sample collection permits. This research was supported by Leonardo da Vinci (HR) training grant with IBAHCM, Marie Curie CIG n 321999 (KRE), an advanced grant of the European Research Council (ERC 293700 GenAdap to AM) and several grants of the Deutsche Forschungsgemeinschaft (AM).

\section{DATA ARCHIVING}

The doi for our data is $10.5061 /$ dryad.d2f 5 b.

\section{LITERATURE CITED}

Alekseyev, S. S., V. P. Samusenok, A. N. Matveev, and M. Y. Pichugin. 2002. Diversification, sympatric speciation, and trophic polymorphism of arctic charr, Salvelinus alpinus complex, in Transbaikalia. Environ. Biol. Fish. 64:97-114.

Arbogast, B. S., S. V. Drovetski, R. L. Curry, P. T. Boag, G. Seutin, P. R. Grant, B. R. Grant, and D. J. Anderson. 2006. The origin and diversification of Galapagos mockingbirds. Evolution 60:370-382.

Barlow, G. W. 1976. The Midas cichlid in Nicaragua. Pp. 333-358 in T. B. Thorson, ed. Investigations of the Ichthyology of Nicaraguan lakes. University of Nebraska Press, Lincoln, NE.

Barlow, G. W., and J. W. Munsey. 1976. The red devil-Midas-arrow cichlid species complex in Nicaragua. Pp. 359-369 in T. B. Thorson, ed. Investigations of the Ichthyology of Nicaraguan Lakes. University of Nebraska Press, Lincoln, NE.

Barluenga, M., and A. Meyer. 2010. Phylogeography, colonization and population history of the Midas cichlid species complex (Amphilophus spp.) in the Nicaraguan crater lakes. BMC Evol. Biol. 10:326.

Barluenga, M., K. N. Stölting, W. Salzburger, M. Muschick, and A. Meyer 2006. Sympatric speciation in Nicaraguan crater lake cichlid fish. Nature 439:719-723.

Barrett, R. D. H., and D. Schluter. 2008. Adaptation from standing genetic variation. Trends Ecol. Evol. 23:38-44.
Bernatchez, L., A. Chouinard, and G. Q. Lu. 1999. Integrating molecular genetics and ecology in studies of adaptive radiation: whitefish, Coregonus sp., as a case study. Biol. J. Linn. Soc. 68:173-194.

Bolnick, D. I. 2004. Can intraspecific competition drive disruptive selection? An experimental test in natural populations of sticklebacks. Evolution 58:608-618.

Bolnick, D. I., and O. L. Lau. 2008. Predictable patterns of disruptive selection in stickleback in postglacial lakes. Am. Nat. 172:1-11.

Bourke, P., P. Magnan, and M. A. Rodríguez. 1999. Phenotypic responses of lacustrine brook char in relation to the intensity of interspecific competition. Evol. Ecol. 13:19-31.

Bunje, P. M.E., M. Barluenga, and A. Meyer. 2007. Sampling genetic diversity in the sympatrically and allopatrically speciating Midas cichlid species complex over a 16 year time series. BMC Evol. Biol. 7:25.

Clabaut, C., P. M. E. Bunje, W. Salzburger, and A. Meyer. 2007. Geometric morphometric analyses provide evidence for the adaptive character of the Tanganyikan cichlid fish radiations. Evolution 61:560-578.

Cole, G. A. 1976. Limnology of the Great Lakes of Nicaragua. Pp. 9-15 in T. B. Thorson, ed. Investigations of the Ichthyology of Nicaraguan lakes. University of Nebraska Press, Lincoln, NE

Coyne, J. A. 2011. Speciation in a small space. Proc. Natl. Acad. Sci. USA 108:12975-12976.

Coyne, J. A., and H. A. Orr. 2004. Speciation. Sinauer Associates, Sunderland, MA.

Dodds, W. K. 2002. Freshwater ecology: concepts and environmental applications. Academic Press, New York.

Elmer, K. R., H. Kusche, T. K. Lehtonen, and A. Meyer. 2010a. Local variation and parallel evolution: morphological and genetic diversity across a species complex of neotropical crater lake cichlid fishes. Philos. Trans. R. Soc. B 365:1763-1782

Elmer, K. R., T. K. Lehtonen, A. F. Kautt, C. Harrod, and A. Meyer. 2010b. Rapid sympatric ecological differentiation of crater lake cichlid fishes within historic times. BMC Biol. 8:60.

Elmer, K. R., A. Meyer. 2011. Adaptation in the age of ecological genomics: insights from parallelism and convergence. Trends Ecol. Evol. 26:298306.

Elmer, K. R., T. K. Lehtonen, S. Fan, and A. Meyer. 2013. Crater lake colonization by Neotropical cichlid fishes. Evolution 67:281-288.

Freundt, A., W. Strauch, S. Kutterolf, and H. U. Schmicke. 2007. Volcanogenic tsunamis in lakes: examples from Nicaragua and general implications. Pure Appl. Geophys. 164:527-545.

Gavrilets, S., A. Vose, M. Barluenga, W. Salzburger, and A. Meyer. 2007. Case studies and mathematical models of ecological speciation. 1. Cichlids in a crater lake. Mol. Ecol. 16:2893-2909.

Gavrilets, S., and J. B. Losos. 2009. Adaptive radiation: contrasting theory with data. Science 323:732-737.

Geiger, M. F., J. K. McCrary, and U. K. Schliewen. 2010a. Not a simple case-a first comprehensive phylogenetic hypothesis for the Midas cichlid complex in Nicaragua (Teleostei: Cichlidae: Amphilophus). Mol. Phylogen. Evol. 56:1011-1024.

Geiger, M. F., J. K. McCrary, and J. R. Stauffer Jr. 2010b. Description of two new species of the Midas cichlid complex (Teleostei: Cichlidae) from Lake Apoyo, Nicaragua. Proc. Biol. Soc. Wash. 123:159-173.

Grant, P. R., and B. R. Grant. 2011. How and why species multiply: the radiation of Darwin's finches. Princeton Univ. Press, Princeton, NJ.

Hindar, K., and B. Jonsson. 1982. Habitat and food segregation of dwarf and normal Arctic charr (Salvelinus alpinus) from Vangsvatnet Lake, western Norway. Can. J. Fish. Aquat. Sci. 39:1030-1045.

Hindar, K., N. Ryman, and G. Stahl. 1986. Genetic differentiation among local populations and morphotypes of Arctic charr, Salvelinus alpinus. Biol. J. Linn. Soc. 27:269-285. 
Holzman, R. A., D. C. Collar, R. S. Mehta, and P. C. Wainwright. 2012. An integrative approach to elucidate suction feeding performance. J. Exp. Biol. 215:1-13.

Jonsson, B., and N. Jonsson. 2001. Polymorphism and speciation in Arctic charr. J. Fish Biol. 58:605-638.

Koblmüller, S., C. Sturmbauer, E. Verheyen, A. Meyer, and W. Salzburger. 2006. Mitochondrial phylogeny and phylogeography of East African squeaker catfish (Siluriformes: Synodontis). BMC Evol. Biol. 6:49.

Kusche, H., H. Recknagel, K. R. Elmer, and A. Meyer. 2014. Crater lake cichlids individually specialize along the benthic-limnetic axis. Ecol. Evol. 4:1127-1139.

Landry, L., W. F. Vincent, and L. Bernatchez. 2007. Parallel evolution of lake whitefish dwarf ecotypes in association with limnological features of their adaptive landscape. J. Evol. Biol. 20:971-984.

Lavin, P. A., and J. D. McPhail. 1985. The evolution of freshwater diversity in the threespine stickleback (Gasterosteus aculeatus): site-specific differentiation of trophic morphology. Can. J. Zool. 63:2632-2638.

Lewontin, R. 1966. On the measurement of relative variability. Syst. Zool. 15:141-142.

Losos, J. B. 2009. Lizards in an evolutionary tree: ecology and adaptive radiation of anoles. University of California Press, Berkeley, CA. . 2010. Adaptive radiation, ecological opportunity, and evolutionary determinism. Am. Nat. 175:623-639.

Losos, J. B., and D. Schluter. 2000. Analysis of an evolutionary species-area relationship. Nature 408:847-850.

Lovette, I. J., E. Bermingham, and R. E. Ricklefs. 2002. Cladespecific morphological diversification and adaptive radiation in Hawaiian songbirds. Proc. R. Soc. B 269:37-42.

MacArthur, R. H., and E. O. Wilson. 1967. The theory of island biogeography. Princeton Univ. Press, Princeton, NJ.

Mahler, D. L., L. J. Revell, R. E. Glor, and J. B. Losos. 2010. Ecological opportunity and the rate of morphological evolution in the diversification of Greater Antillean anoles. Evolution 64:2731-2745.

Matschiner, M., R. Hanel, and W. Salzburger. 2011. On the origin and trigger of the notothenioid adaptive radiation. PLoS One 6:e18911.

McPhail, J. D. 1993. Ecology and evolution of sympatric sticklebacks (Gasterosteus): origin of the species pairs. Can. J. Zool. 71:515523.

1994. Speciation and the evolution of reproductive isolation in the sticklebacks (Gasterosteus) of south-western British Columbia. Pp. 399437 in M. Bell and S. Foster, eds. The evolutionary biology of the threespine stickleback. Oxford Univ. Press, Oxford, U.K.

Meyer, A. 1990. Morphometrics and allometry in the trophically polymorphic cichlid fish, Cichlasoma citrinellum: alternative adaptations and ontogenetic changes in shape. J. Zool. 221:237-260.

- 1993. Phylogenetic relationships and evolutionary processes in East African cichlid fishes. Trends Ecol. Evol. 8:279-284.

Meyer, J. R., and R. Kassen. 2007. The effects of competition and predation on diversification in a model adaptive radiation. Nature 446:432435.

Near, T. J., R. I. Eytan, A. Dornburg, K. L. Kuhn, J. A. Moore, M. P. Davis, P. C. Wainwright, M. Friedman, and W. L. Smith. 2012. Resolution of ray-finned fish phylogeny and timing of diversification. Proc. Nat. Acad. Sci. USA 109:13698-13703.

Norton, S. F., and E. L. Brainerd. 1993. Convergence in the feeding mechanics of ecomorphologically similar species in the Centrarchidae and Cichlidae. J. Exp. Biol. 176:11-29

Nosil, P., and B. J. Crespi. 2004. Does gene flow constrain adaptive divergence or vice versa? A test using ecomorphology and sexual isolation in Timema cristinae walking-sticks. Evolution 58:102-112.
Nosil, P., and T. E. Reimchen. 2005. Ecological opportunity and levels of morphological variance within freshwater stickleback populations. Biol. J. Linn. Soc. 86:297-308

Østbye, K., P. A. Amundsen, L. Bernatchez, A. Klemetsen, R. Knudsen, R. Kristoffersen, T. Naesje, and K. Hindar. 2006. Parallel evolution of ecomorphological traits in the European whitefish Coregonus lavaretus (L.) species complex during postglacial times. Mol. Ecol. 15: 3983-4001.

Parent, C. E., and B. J. Crespi. 2009. Ecological opportunity in adaptive radiation of Galapagos endemic land snails. Am. Nat. 174:898-905.

R Core Team. 2012. R: a language and environment for statistical computing. $\mathrm{R}$ foundation for statistical computing, Vienna, Austria. Available at http://www.R-project.org/.

Rainey, P. B., and M. Travisano. 1998. Adaptive radiation in a heterogeneous environment. Nature 394:69-72.

Räsänen, K., and A. P. Hendry. 2008. Disentangling interactions between adaptive divergence and gene flow when ecology drives diversification. Ecol. Lett. 11:624-636.

Recknagel, H., H. Kusche, K. R. Elmer, and A. Meyer. 2013. Two new endemic species in the Midas cichlid species complex from Nicaraguan crater lakes: Amphilophus tolteca and Amphilophus viridis (Perciformes, Cichlidae). Aqua 19:207-224.

Reed, D. H., and R. Frankham. 2001. How closely correlated are molecular and quantitative measures of genetic variation? A meta-analysis. Evolution 55:1095-1103.

Renaut, S., A. W. Nolte, S. M. Rogers, N. Derome, and L. Bernatchez. 2011. SNP signatures of selection on standing genetic variation and their association with adaptive phenotypes along gradients of ecological speciation in lake whitefish species pairs (Coregonus spp.). Mol. Ecol. 20: 545-559.

Ricklefs, R. E., and I. J. Lovette. 1999. The roles of island area per se and habitat diversity in the species-area relationships of four Lesser Antillean faunal groups. J. Anim. Ecol. 68:1142-1160.

Robinson, B. W., D. S. Wilson, A. S. Margosian, and P. T. Lotito. 1993. Ecological and morphological differentiation by pumpkinseed sunfish in lakes without bluegill sunfish. Evol. Ecol. 7:451-464.

Salzburger, W., T. Mack, E. Verheyen, and A. Meyer. 2005. Out of Tanganyika: genesis, explosive speciation, key-innovations and phylogeography of the haplochromine cichlid fishes. BMC Evol. Biol. 5:17-31.

Schluter, D. 1993. Adaptive radiation in sticklebacks - size, shape, and habitat use efficiency. Ecology 74:699-709.

. 2000. The ecology of adaptive radiation. Oxford Univ. Press, Oxford, U.K.

Schluter, D., and J. D. McPhail. 1992. Ecological character displacement and speciation in sticklebacks. Am. Nat. 140:85-108.

Seehausen, O., Y. Terai, I. S. Magalhaes, K. L. Carleton, H. D. J. Mrosso, R. Miyagi, I. van der Sluijs, M. V. Schneider, M. E. Maan, H. Tachida, et al. 2008. Speciation through sensory drive in cichlid fish. Nature 455:620-626.

Stauffer J. R. Jr., and K. R. McKaye. 2002. Descriptions of three new species of cichlid fishes (Teleostei: Cichlidae) from Lake Xiloá, Nicaragua Cuadernos de Investigación de la U.C.A. 12: 1-18.

Stauffer, J. R. Jr., J. K. McCrary, and K. E. Black. 2008. Three new species of cichlid fishes (Teleostei: Cichlidae) from Lake Apoyo, Nicaragua. Proc Biol. Soc. Wash. 121:117-129.

Svanbäck, R., and D. I. Bolnick. 2007. Intraspecific competition drives increased resource use diversity within a natural population. Proc. R. Soc. Lond. B 274:839-844.

Turner, G. F. 2007. Adaptive radiation of cichlid fish. Curr. Biol. 17:R827R831. 
Vamosi, S. M. 2003. The presence of other fish species affects speciation in threespine sticklebacks. Evol. Ecol. Res. 5:717-730.

Vivas, R., and K. R. McKaye. 2001. Habitat selection, feeding ecology, and fry survivorship in the Amphilophus citrinellus species complex in Lake Xiloá. J. Aquacult. Aq. Sci. IX:32-48.

Vonlanthen, P., D. Roy, A. G. Hudson, C. R. Largiader, D. Bittner, and O. Seehausen. 2009. Divergence along a steep ecological gradient in lake whitefish (Coregonus sp.). J. Evol. Biol. 22:498-514.

Wagner, C. E., L. J. Harmon, and O. Seehausen. 2012. Ecological opportunity and sexual selection together predict adaptive radiation. Nature 487:366369.
Waid, R., R. Raesly, K. McKaye, and J. McCrary. 1999. Zoogeografía íctica de lagunas cratéricas de Nicaragua. Encuentro 51: $65-80$.

Webb, P. W. 1984. Body form, locomotion and foraging in aquatic vertebrates. Am. Zool. 24:107-120.

Wilson, A. B., K. Noack-Kunnmann, and A. Meyer. 2000. Incipient speciation in sympatric Nicaraguan crater lake cichlid fishes: sexual selection versus ecological diversification. Proc. R. Soc. Lond. B 267:21332141 .

Associate Editor: T. Streelman

\section{Supporting Information}

Additional Supporting Information may be found in the online version of this article at the publisher's website:

Table S1. Collinearity between variables.

Table S2. Rotation of the six included predictive variables on the six principal components of the PCA.

Table S3. Phenotypic characteristics ( $\mathrm{EI}_{\mathrm{MEAN}}, \mathrm{EI}_{\mathrm{MIN}}$, and $\mathrm{EI}_{\mathrm{MAX}}$ ) and morphological variability $\left(\mathrm{CV}_{\mathrm{EI}}\right)$ of Midas cichlid flocks regressed against principal components of a PCA of all combined predictive variables (genetic diversity, lake surface, lake age, littoral zone area, competing species, and lake depth). Figure S1. Principal component analysis (PCA) of the six predictive lake specific parameters (littoral zone area, number of competing species, genetic diversity, lake surface, lake age, and mean lake depth). 